\title{
Mobile Technology for Students \& Adults with Autistic Spectrum Disorders (ASD)
}

\author{
https://doi.org/10.3991/ijim.v11i1.5922 \\ Jenny A. Vlachou \\ National Center for Scientific Research, Athens, Greece \\ jvlachou@gmail.com \\ Athanasios S. Drigas \\ National Center for Scientific Research, Athens, Greece \\ dr@iit.demokritos.gr
}

\begin{abstract}
This study evaluates the use and efficacy of mobile technology so as to provide assessment and treatment intervention to children and adults with Autistic Spectrum Disorders (ASD). Learning and behavioural data for assessment can be captured and interpreted through mobile technology, but the complexity of this data in special education can sometimes discourage staff from using it. Mobile technology intervention, in conjunction with ad hoc applications for ASD individuals, can contribute to the individuals' needs to a great extent. Needless to say, speech generating devices (SGDs) are very supportive tools for autistic people who mostly suffer from limited speech, especially devices which are portable. The use of mobile technology to enhance academic skills, among others, is being investigated. Although this technology is new, the autistic community has expressed its enthusiasm about it. If all parties involved, such as educators, caregivers, sufferers and families participated in the design and implementation of the appropriate apps, this could best suit ASD individuals' needs and would provide them with a better quality of life.
\end{abstract}

Keywords - assessment, ICT, intervention, ASD, developmental disabilities, Augmentative and Alternative Communication (AAC), Computer Assisted Learning (CAL), Computer Assisted Instruction (CAI), mobile technology, iPad, iPod, iPhone, tablet, smartphone, children with autism (CWA). 


\section{Introduction}

\subsection{Autism Spectrum Disorders (ASD)}

Autism is a disorder which appears early in childhood and there is no apparent reason behind the cause. At present time, there is no cure for this. Despite the fact that the child can become an autistic adult, early diagnosis will allow for more effective treatment. Current statistics show that autism affects up to two children in every thousand, and that it is three times more likely to affect boys than girls [1]. There are no 'standard' symptoms, only those which are more common. These can include an impairment of non-verbal communication, a lack of spontaneous activity and a dependence on repetitive actions. As a result, the autistic person appears to be closed off in their own world, a world in which normal social skills are impaired. A typical autistic child does not attempt to get attention unless it is to fulfill a need, which would therefore need to be provided by another person.

As a result, the child seems to be ignoring the world at large and is usually very resistant to external interaction and communication [21]. A number of treatments have been put forward for the cure of autism. Among these are treatments which are efficiently carried out by technology such as the ones that will be analysed in the present study.

\subsection{Mobile Technology}

Mobile devices have gained popularity within the special needs community. These mobile devices are the "cool new" gadgets, unlike the previous, complex and "I-amnot-normal-looking" assisting devices. These mobile devices are said to serve as a communication device in the pocket, a learning device on the go and even a lifesaver for some. Its features include flexible multimedia content and storage, portability, mobility and affordability. The touch screen interface makes it appealing and simple to use, particularly for those who have weak motor skills. It offers practical communication solutions for autistic people, so that they can interact with their families and others in the community. The flexibility and the advanced capabilities of mobile technology are opening new opportunities for further research in the area of computerbased intervention for children with ASD. Several anecdotal reports give an early indication of the immense possibilities of how these devices could play a significant role in enhancing the quality of life for children with ASD and their families. There is definitely a lack of published research studies on the use of mobile technology among children with ASD. Due to the growing popularity of adopting mobile devices as assisting devices, more in depth research is warranted [2]. 


\section{Mobile Technology Tools}

\subsection{Mobile Tools for Assessment}

The effectiveness of receiving informative feedback for the purpose of updating the assessment and diagnosis of children with autism (CWA), as well as the therapeutic interventions, are presented by Gillian R. Hayes et al. (2014) in their review paper. The study took place at the Emory Autism Research Center located at the Walden School. This center provides services for CWA. This study included the development of three prototype capture and access applications: (1) The Walden Monitor, a wearable prototype for recording observable data, with a head-mounted bullet camera based on a Tablet PC for the research assistant to capture the child's data. (2) Abaris, an Environmental Prototype for Recording Discrete Trial Data where therapists use a tablet application to customize the child's daily therapy and to record data. (3) CareLog, a distributable prototype for recording semi-structured data that consists of a mobile system using the configuration of capture and access devices designed to collect this information. The findings were that predetermined capture and access applications are not flexible enough to support the cyclical activities involved in caring for CWA, unless end users are able to iterate on the capture and access applications. Thus, it is critical that end users be involved in the process of developing capture and access applications, services and data integration processes in future applications [3]. The reasons why paper persists in the workplace of special education instead of technology for collection and use of student data is discussed in the paper of Gabriela Marcu et al. (2013). The staff itself, is positive towards trying new technologies provided that it supports their work practices and that they see evidence of success. The authors attempt to enumerate various technological devices and software such as the Abaris system for autism therapy, the AMA tablet application for data analysis and five mobile applications for iPads, such as: ABC DATA Pro, Autism Tracker Pro, Behavior Journal, Behavior Tracker Pro and Catalyst HD. However, the problem lies with the fact that special education does not have standardised or well established work practices, due to the individualised needs of each student and the unpredictable nature of the special education environment. In more detail, six factors affected the result of data collection in special education. Three of these factors explained why paper substitutes technology use and these are:

1. Data needs are complex and not standardised

2. Immediate demands of the job interfere with thorough in situ data collection

3. Existing technology for data collection is inadequate data:

The other three factors explain why technology could improve sharing and use of

1. Data sheets are idiosyncratic and not useful without human mediation

2. Improved communication with parents could benefit children's development

3. Staff are willing and even eager to incorporate technology 
Technology benefits can be augmented in the future, especially if data is collected in situ which is critical in autism education [4].

\subsection{Mobile Tools for Intervention}

Using mobile technology, for people with special education needs (SEN) in all domains of life seems very promising lately.

Debora M. Kagohara et al. (2013) conducted a review of studies that involved iPods, iPads and related devices in teaching programs for individuals with developmental disabilities. The examination of 15 studies reported results for 47 individuals aged from 4 to 27 years old with autism spectrum disorder (ASD) and/or intellectual disabilities. It focused on five domains: (a) academic, (b) communication, (c) employment, (d) leisure and (e) transition across school settings.

The main objectives of the review were to: (a) describe the skills that have been successfully taught to individuals with developmental disabilities using iPod/iPadbased instruction, (b) describe the software applications that have been used with these iPod/iPad-based instructional programs and (c) gain an overall view of the effectiveness of iPod/iPad-based instruction for this population. These devices and associated software applications have been used to either (i) deliver instructional prompts via the iPod Touch or iPad or (ii) teach the person to operate an iPod Touch or iPad to access preferred stimuli or as a speech-generating device (SGD) to request preferred stimuli. The results of these 15 studies were very encouraging suggesting that iPods, iPod Touch, iPads and related devices are viable technological aids for individuals with developmental disabilities. An important direction for future research is to use such devices for other communicative purposes such as greetings, conversations and comments [5].

The three major domains of intervening mobile tools will be thoroughly analysed next.

Intervening Mobile Tools for Augmentative or Alternative Communication (AAC) In 2014, Sue Fletcher-Watson conducted a review on Computer-Assisted Learning (CAL) for people with autism spectrum disorder. New technologies are helping to break down some of the objections to computer assisted learning (CAL). Some people argue that CAL can only be delivered effectively in schools with lots of computers and that there is a lower ability limit on who can benefit. However CAL is being overtaken by technologically-enhanced approached similar to mobile devices. Even though a device such as an iPad carries a considerable price tag, once purchased the user has access to hundreds of low-priced apps marketed at people with autism and thousands more which may also be appealing. Communication apps such as Proloquo2Go or Speak4Yourself come with the promise of giving a non-verbal person with autism a voice. The rise of mobile devices such as Smartphones and the now wide-spread use of touchscreen technology invites new ways of thinking about education and support for people with autism spectrum disorders. In an early example of his work, Bishop (2003) reports on the use of a mobile phone application called PARLE (Portable Affect Reference Learning Environment) which can be used to translate confusing language such as metaphors into simpler versions. Case studies indicate 
that PixTalk software can be incorporated into an on-going therapy. Mechling and his colleagues have successfully trialed the use of a personal digital assistant to support both abstract and real world skills by using step-by-step prompts [6],[7].

Lizbeth Escobedo et al. (2012) study the Mobile Social Compass titled "MOSOCO", a mobile assisting application that uses augmented reality and the visual supports of a validated curriculum, the Social Compass, to help children with autism practise social skills in real-life situations. They present the results of a seven-week deployment study of MOSOCO in a public school in Southern California with both autistic students and neurotypical (NT) students.

MOSOCO provides autistic children with interactive features to encourage them to make eye contact, maintain appropriate spatial boundaries, reply on conversational initiators, share interests with partners, disengage appropriately at the end of an interaction and identify potential communication partners. MOSOCO runs on an Android smartphone which is wirelessly connected to a server. It uses the smartphone's camera to augment a real-life social situation with visual support mimicking the Social Compass curriculum which augments social stories using paper-based visual supports.

The results of the study demonstrate that MOSOCO facilitates practicing and learning social skills, increases both quantity and quality of social interactions, reduces social and behavioural mistakes, and enables the integration of children with autism in social groups of neurotypical children [8].

Doris Adams Hill and Margaret M. Flores (2014) compared the Picture Exchange Communication System and the $\mathrm{Pad}^{\mathrm{TM}}$ for the Communication of students with $\mathrm{Au}-$ tism Spectrum Disorder and Developmental Delay.

The Picture Exchange Communication System (PECSTM), a picture-based, lowtech augmentative and alternative communication strategy developed by Frost and Bondy (2002), utilises preference for visual processing as well as the principles of Applied Behavior Analysis (ABA) to teach functional communication skills to individuals without that ability. PECS ${ }^{\mathrm{TM}}$ training occurs in six phases. It begins with teaching how to communicate (Phase I) and moves through five other phases which include increasing distance from the communicative partner (Phase II), picture discrimination (Phase III), sentence structure (Phase IV), responding to "What do you want?"(Phase V) and commenting (Phase VI).

There are $\mathrm{iPad}^{\mathrm{TM}}$ applications designed to facilitate its use as a communication system. One such application is Proloquo $2 \mathrm{Go}^{\mathrm{TM}}$ which provides augmentative and alternative communication (AAC) for people who have difficulty in speaking. It provides text-to-speech voices, colour picture symbols and a vocabulary of over 7000 items (Apple, 2011; Assistiveware, 2011). Utilising the iPad ${ }^{\mathrm{TM}}$ with the Proloquo2go application as AAC can be used by individuals of all ages, is inexpensive compared to some devices and also portable.

Each student was scheduled to experience eight sessions using PECS ${ }^{\mathrm{TM}}$ (Bondy \& Frost,1994) and seven sessions using the $\mathrm{Pad}^{\mathrm{TM}}$.

The results of this study were mixed, with students responding differently to each communication intervention. This lack of difference is significant for the field because it shows that limited technological intervention can be as or more effective than more advanced technology. An intervention such as PECS might be preferable during 
the early stages of communication development. It would also make sense that the $\mathrm{iPad}^{\mathrm{TM}}$ be preferable once the student has developed a communication repertoire.

It is important that early intervention strategies involving empirically-based interventions be used to influence a positive outcome for students with autism and developmental delay (DD) (National Autism Center, 2009). This study focused on comparing the use of PECS ${ }^{\mathrm{TM}}$ and the $\mathrm{iPad}^{\mathrm{TM}}$ for the purpose of requesting. As a result, it is recommended that initial functional communication training begin with PECSTM and then with a transition from PECS ${ }^{\mathrm{TM}}$ (after mastery of phases I-III) to the $\mathrm{PPad}^{\mathrm{TM}}$. This could be a viable teaching progression of functional communication skills for some students with ASD or DD. The authors contend that this is worthy of additional research [9].

Maggie Ward et al. (2013) evaluated an iPad application titled "Go Talk Now Free" as a functional communication tool for a five-year-old boy with ASD, through their study. This application is similarly formatted to the traditional Picture Exchange Communication System (PECS) request board, making all the choices visibly available for the child to select on a single touch screen page on the application. The study that took place in the participant's special education classroom required: (1) children to bring whichever activity they chose into the classroom ("the choose time") during the baseline strategy, (2) researchers to successfully teach the participant how to make requests and test the use of the model, lead, test intervention strategy which was the purpose of this study and (3) researchers to provide no further verbal or physical prompting apart from the question "What do you want?" when presenting the iPad choose board to the participant during the independent strategy. The use of the iPad app "Go Talk Now Free" as functional communication proved to be successful for the participant, and a contributor to his success could have been his familiarity with using the iPad. Based on the success shown in this study, the researcher hopes that the participant will generalise his knowledge of making independent requests by simply "choosing time" to "requesting" throughout the entire school day [10].

In 2013, David Mc Naughton and Janice Light point out in their paper that the iPad and other mobile technologies provide powerful new tools to potentially enhance communication for individuals with developmental disabilities, acquired neurogenic disorders and degenerative neurological conditions. These mobile technologies offer a number of potential benefits including: (a) increased awareness and social acceptance of augmentative and alternative communication (AAC), (b) greater consumer empowerment in accessing AAC solutions, (c) increased adoption of AAC technologies, (d) greater functionality and interconnectivity and (e) greater diffusion of AAC research and development. However, there are a number of significant challenges remaining that must be addressed if these benefits are to be fully realized: (a) to ensure the focus is on communication, not just technology, (b) to develop innovative models of AAC service delivery to ensure successful outcomes, (c) to ensure ease of access for all individuals who require AAC and (d) to maximize AAC solutions to support a wide variety of communication functions. Finally, research should consider the effects of iPads and other mobile technologies on the ASD's facilitators: family members, teachers, etc., as well as making sure that the most complex communication needs are satisfied [11]. 
Amie M. King et al. (2013) conducted a study to describe how children and young adults with autism spectrum disorder (ASD) are currently using $\operatorname{iPads}{ }^{\circledR}$ and applications. The purpose was to explore application use and the role of educational professionals on the $\mathrm{iPad} \AA$ as well as determining potential research needs regarding $\mathrm{iPad} \AA$ use in people with ASD. Six individuals (ages 6;6 to 20;8) with ASD were observed while they were using iPads ${ }^{\circledR}$ and apps in their classroom. The apps were categorized into: (1) augmentative and alternative communication (AAC) apps which represented $51 \%$ of the app time spent, (2) academic apps, with $36 \%$ and (3) game apps with only $13 \%$ of the app time spent. The observation included video data and the recording sessions occurred randomly so as to capture different behaviours throughout all activities. There were five phases in which the data were coded: (i) In the $1^{\text {st }}$ phase, all of the video data were reviewed repeatedly by the first and third authors. (ii) In the $2^{\text {nd }}$, the video data were filtered to exclude behaviours that provided irrelevant information to the study. (iii) The $3^{\text {rd }}$ phase involved coding time spent in the different $\operatorname{iPad}{ }^{\circledR}$ environments. (iv) The fourth phase of data coding consisted of indicating the presence or absence of an educational professional and the last one (v) involved further analysis on how the 28 apps were used by the participants. If the app was used in a way that was inconsistent with its intended function, it was characterized as a violation of the app which was a unique finding of this study. The final outcome of the study was that iPads being used at schools support ASD individuals. As long as there is an educational professional present, violation of apps is less likely to occur [12].

Sally Bereznak et al. (2012) conducted research in the field of video self-prompting and mobile technology to find out if these increase the capability of day-to-day living and vocational independence for students with autism spectrum disorders. Video instruction can include video modelling (VM) and/or video prompting (VP). In the current investigation, they essentially provided a prosthetic device (iPhone) and training to help the participants become more independent. In doing so, they linked a number of elements of self-determined, self-efficacy and independence.

The current study addressed two research questions related to video prompting in order to teach individuals with ASD. These questions focused on whether students would be able to learn how to use an iPhone as a self-prompting video tool to teach themselves vocational and independent living tasks and if they would be able to independently complete them when using video prompting. The study furthered the evaluation of handheld commercially-designed devices as an effective teaching tool for individuals with ASD as long as motor difficulties were not involved. The percentage of success when using the iPhone for completing the tasks was much higher than the one which guided them only through the baseline sessions.

Further research is needed to describe effective techniques which can benefit individuals with ASD for potential employment opportunities so that they can efficiently and effectively follow through with various tasks without the assistance of others. (Mechling et al. 2009a, 2009b) [13].

Debora M. Kagohara et al. (2010) suggest an alternative solution for individuals with autism and limited speech. These individuals are prime candidates for speech generating devices (SGDs) yet face problems with these devices. SGDs are typically computer-based devices with a visual display and either have a digitised or synthe- 
sized speech output. Up till now, it was common for people who could not use these devices to be prescribed a different SGD or otherwise adapt to this existing device, both of which were quite costly. An other option was to give up using this type of technology. However, this was not a good solution either since SGDs provide one of the most complete forms of communication among all AACs, due to their assisting speech features. In Steven's case, an autistic 17-year-old adolescent who used an iPod SGD and had difficulty activating the speech output feature, a behavioural intervention with differential reinforcement and delayed prompting was suggested. Specifically, he used the i-Pod touch with Proloquo2Go software that he was prescribed with. He encountered difficulty in enabling the speech so alternatively a person was there to assist him in order to determinate if the problem was due to lack of motor control or if he was in need of behavioural intervention. The results showed that he corresponded positively to behavioural intervention and finally managed to complete the task of enabling the speech feature on his own by the required time [14].

Intervening Mobile Tools for Academic: Larah van der Meer et al. (2015) mention in their paper that iPads have been successfully used as speech-generating devices (SGDs) for children with ASD and limited speech. However, little research has investigated the use of iPads to enhance academic skills such as picture/word matching. In the present study, a student with ASD received assistance in being taught picture and word matching by using an iPad-based SGD as a response mode. A multiple baseline across matching tasks design was used to evaluate the effects of a graduated guidance, prompting procedural and differential reinforcement on correct matching across four matching tasks (i.e. picture to picture, word to picture, picture to word and word to word). Targeting both picture and word matching is relevant to a range of academic/literacy skills. This technology may enable such students to participate in such academic/literacy skill tasks that they may otherwise be excluded from.

Results indicate that the participant successfully learned picture and word matching with an iPad-based SGD as the response mode. Furthermore, the teaching procedures appeared to be effective in reducing repetitive responding and keeping the mind clear when the order in which pictures were presented was randomised. Future research is needed, though, to investigate the long-term effects that iPods/iPads may have on learning [15].

Leslie Neely et al. (2013) discuss the effects of using an iPad for instructional purposes with regards to challenging behaviour and academic engagement. In recent years, the Apple iPad has emerged as a popular educational form of technology for individuals on the autism spectrum. This study compared the behaviour of two students with ASD and escape-maintained challenging behaviour, when academic instruction was delivered via an iPad and when delivered through traditional materials. A reversal A-B-A-B design was implemented to deliver instruction using traditional materials in the first phase and instruction via the iPad in the second phase. Both children showed lower levels of challenging behaviour and higher levels of academic engagement during the iPad situation whereas in the traditional materials situation, they showed higher levels of challenging behaviour with lower levels of academic engagement. As a result, there is an advantage of using the iPad because it seems to reduce escape-maintained behaviour in ASD children. Future research is warranted, 
though, to investigate the duration of the iPad's effects as this form of technology is fairly new [16].

In 2014, Therese M. Cumming et al. did a research project on the introduction of iPads as instructional tools in order to enhance learning opportunities for students with developmental disabilities at a private school in Sydney. The core questions that teachers were addressing through this action research were: (a) How mobile devices such as iPads can assist and enhance learning opportunities among students.

(b) What the perception of students with developmental disabilities and their teachers is in regard to using the iPad as an instructional tool. Both questions were wellaligned with the UDL model.

The results related to the first question were well received by both teachers and students. What was obvious from the data analysis was that iPads have enhanced learning opportunities for students. The iPad was beneficial to students in the general areas of access, learning, independence and engagement. They worked independently on all their subjects through the use of iPad apps and most importantly through communication which was assisted by the Proloquo 2 app in a certain case. With regard to the second one, students found the technology effective in terms of reading instruction, vocabulary development and communication, as well as being fun and motivating. To fully test the effectiveness of the iPads, the addition of more stringent, qualitative and quantitative data collection and analysis on student achievement is warranted for the future. In addition, research on tablet integration should be conducted across other settings and types of schools such as ones with no prior familiarisation with certain technology within the home [17].

In their study, Cathi Draper Rodríguez et al. (2013) show that implementing and using iPads in the special education classroom is very effective. Based on literature, suggestions on the planning and implementation of iPad technologies are as follows: (1) Planning for mobile technology in the classroom. Logistical preplanning must occur to ensure that the instructional time is used effectively, such as when students will use the devices, how many students will use the device at one time and what the rules are for use and how they will be taught. (2) Rubrics for choosing apps. Due to the large variety of educational apps in the market, it would be helpful for educators to access educational and behavioural app review sites or to use an evaluation rubric to determine the best applications for individual student needs. (3) Bulk buying for apps. Charging and syncing multiple devices can be a challenge for teachers purchasing apps. IPad and iPod devices can be purchased through Apple's volume purchase program. Apps for Android tablets can be purchased in bulk through Chrome App Packs. (4) Professional development. Self-efficacy among teachers with regard to using mobile devices as educational or assisting technology is an integral component of successful implementation (Messinger-Willma \& Marino, 2010). Professional development through mobile learning is offered to groups, face-to-face and online or by showing interest in research projects within this field at a low cost. (5) Schoolhome communication/collaboration. This is important for the families of students with disabilities. According to their needs, students are able to personalize their features on their tablet. Therefore, parents will be able to take part in the required tasks along with their children. Parent training, as well as the teacher's assistance, can en- 
courage involvement among all parties in order to support the student both at school and at home. (6) Transition between environments. The transition between school and the community can greatly benefit students with disabilities when using mobile devices as an assisting tool. With the tips mentioned above, teachers can increase the effectiveness of using technology with the hope of increasing the engagement and satisfaction in their classrooms [18].

Cami E. Burton et al. (2013) conducted a study on Video Self-Modelling (VSM) with an iPad to teach functional mathematical skills to adolescents with Autism and Intellectual Disability.

Functional mathematics focuses on teaching practical mathematics within real-life situations such as telling the time, using money and completing tasks related to measurement. Four adolescent male students viewed videos of themselves on an iPad solving mathematical problems in order to estimate the amount of money used to pay for a given item and the amount needed to receive in change. A multiple-baseline-acrossparticipants design to investigate the effects of VSM on the mathematical skill acquisition of adolescents with autism was used. The design included baseline, intervention and post-intervention phases. The outcome was that VSM intervention allowed students with disabilities to increase their access to the core curriculum without teacher assistance. Additional research is needed to examine the use of VSM via an iPad to teach students with autism and intellectual disabilities a variety of academic subjects such as science, reading and writing [19].

Heather Duncan, Joo Tan (2012) describe a project idea in their paper to design and implement a mobile web application on iPad2 that would allow adults with autism to complete their work with minimal supervision. Supervision is often an obstacle for employment since employers are not fond of providing job coaches or supervising their autistic employees themselves. This application would aim to reduce the amount of supervision as it would act as a visual task manager or as a supervisor. One important feature of the application would be the ability to split each task into small "inner steps" that would signify its completion. Another one would be to include a communication system that would allow both image-based and text-to-speech communication. Having a number of customization options, providing Wireless Internet functionality and offering the ability to create video, animation or photo slideshows would enhance the ability of the schedule to convey the inner steps of a task to the autistic individual. The ongoing research would be divided into two major phases. Phase one would focus on functionality that is related to the end user (the autistic individual) interface. Phase two (future) of this research would involve supervisor functions such as creating/updating the tasks, including storage capability and adding security features [20].

Intervening Mobile Tools for Entertainment: In their paper, Iain Werry et al. (1999) discuss how mobile robotics are able to aid disabled, handicapped or autistic people. Through the AuRoRA (Autonomous Robotic platform as a Remedial tool for children with Autism) research project, Mobile Robotic Technology can be useful in a scientifically challenging application area named the rehabilitation of children with autism. It has the potential to advance our understanding of human-robot interface design, as well as aid in the rehabilitation of the autistic people. This is attempted 
through the TEACCH philosophy method which guides the robotic platform to provide the necessary stimulation to re-enforce the child's responses. Additionally, what is needed the most in the autistic world is:

- a stable environment through repetitive actions

- keeping away the fear of the unpredictable

- keeping the child's attention by stretching its interactive and communicative abilities,

all of which can be provided by the robot.

The initial robot, a Labo-1 mobile platform, has sensors for input information and two buttons for behavioural selection. However, future developments are expected to have more sensors, a camera, an optional speech device and advanced machinelearning capabilities so as to adapt continually and provide enjoyable life-like experiences [21].

Through their research, Juan Pablo Hourcade et al. (2013) evaluate weather tablet apps can encourage social interaction in children with autism spectrum disorders. The set of apps - Drawing, Music, Untagle and Photogoo - which are all from Open Autism Software aim to help children with ASD associate social face-to-face interaction with playing. It is true that positive feelings came out of the children when they initiated with tablets because they were not anxious over the presence of an unpredictable person. The apps have very simple user interfaces with little or no use of words to better appeal. There is also no right or wrong way of doing things with the apps. Children are able to explore the apps, express themselves freely and also reduce anxiety.

It was also investigated as to whether activities with multi-touch tablet apps promoted better social behaviour over activities without tablets. This appeared to be a fact, where video recordings attributed to the results through capturing the children's faces and body gestures.

More specifically, the types of events they coded, among others, were: verbal interactions, supportive comments between kids and physical interactions. These three made a positive difference when students socialised through tablets rather than doing the activities without them [22].

The present study by Debora M. Kagohara (2010) examines whether students with developmental disabilities can learn to self-operate an iPod Touch in order to watch entertaining videos with video modelling (VM) and response prompting. Three students were selected for this study. They all attended the same classroom in a specialised school for adolescents and young adults with a range of disabilities. A questionnaire was created to give the participants as stakeholders an opportunity to consent to their involvement in the study and to identify preferred stimuli for use in the study. The questionnaire seemed to have a positive influence since the participants felt their opinion mattered. All participants indicated that they were interested in learning how to use the iPod and provided a list of what they liked to watch. They also indicated that watching a video was one of their preferred methods for learning. The aim of the study was to motivate students to participate and to teach them how to operate the iPod in order to watch their preferred entertainment videos. Future research could 
determine whether participants might be differentially sensitive to other iPod-based leisure skills such as playing video games or listening to music [23].

\section{Conclusion}

In conclusion, mobile technology is very appealing to all children, especially to those with ASD, who lack communication skills but are eager to play with a portable device. Predicted responses from a mobile device do not cause any anxiety to these children, thus have a gamesome attitude and feel more secure.

Mobile technology assessment tools are very important, not only for the initial diagnosis of autism, but for updating the sequent assessments throughout a patient's therapeutic intervention. It is found that a continual observation of the patient's behaviour will end up receiving the correct diagnosis and can only be achieved by a mobile device that records constantly.

Despite the fact that capturing data for assessment can sometimes be a tedious task with ongoing mobile technologies, due to the data's complexity, the assessment personnel is optimistic and receptive to new approaches.

Mobile technology tools for intervention are quite promising, too at present and progress has already been made in ASD individuals as shown by the statistics. There is always enough space for further development, though, and better applications for the ASDs especially if these are implemented by all parties, such as family members, educators and therapists who are involved in the rehabilitation of the autistic people.

\section{$4 \quad$ References}

1. Colwyn Trevarthen (1996) Lateral asymmetries in infancy: Implications for the development of hemispheres. URL: http://www.sciencedirect.com/science/article/pii/014976 3495000704 https://doi.org/10.1016/0149-7634(95)00070-4

2. Helena Song Sook Yee (2012) Mobile technology for children with Autism Spectrum Disorder: Major trends and issues. URL: http://ieeexplore.ieee.org/xpl/login.jsp?tp=\&arnu mber=6414954\&url=http\%3A\%2F\%2Fieeexplore.ieee.org\%2Fxpls\%2Fabs all.jsp \%3Farn umber $=6414954$

3. Gillian R. Hayes, Julie A. Kientz, Khai N. Truong, David R. White, Gregory D. Abowd, Trevor Pering (2004) Designing Capture Applications to Support the Education of Children with Autism. URL: http://link.springer.com/chapter/10.1007/978-3-540-30119-6_10

4. 1.Gabriela Marcu, Kevin Tassini, Quintin Carlson, Jillian Goodwyn, Gabrielle Rivkin, Kevin J. Schaefer, Anind K. Dey, Sara Kiesler (2013) Why do they still use paper? Understanding data collection and use in autism education URL: http://dl.acm.org/citation.cfm?id=2466436

5. Debora M. Kagohara, Larah van der Meer, Sathiyaprakash Ramdoss, Mark F. O'Reilly, Giulio E. Lancioni, Tonya N. Davis, Mandy Rispoli, Russell Lang, Peter B. Marschik, Dean Sutherland, Vanessa A. Green, Jeff Sigafoos (2013) Using iPods and iPads in teaching programs for individuals with developmental disabilities: A systematic review URL: http://www.sciencedirect.com/science/article/pii/S0891422212001941 https://doi.org/10. 1016/j.ridd.2012.07.027 
6. Linda C. Mechling, Erin J. Savidge (2011) Using a personal digital assistant to increase completion of novel tasks and independent transitioning by students with autism spectrum disorders. URL: http://link.springer.com/article/10.1007/s10803-010-1088-6 https://doi.org/10.1007/s10803-010-1088-6

7. Sue Fletcher-Watson (2014) A Targeted Review of Computer-Assisted Learning for People with Autism Spectrum Disorder: Towards a Consistent Methodology. URL: http://link.springer.com/article/10.1007/s40489-013-0003-4 https://doi.org/10.1007/s40489 -013-0003-4

8. Lizbeth Escobedo, David H. Nguyen, LouAnne Boyd, Sen H. Hirano, Alejandro Rangel, Daniel García-Rosas, Monica Tentori, Gillian R. Hayes (2012) MOSOCO: A Mobile Assistive Tool to Support Children with Autism Practicing Social Skills in Real-Life Situations. URL: http://dl.acm.org/citation.cfm?id=2208649 https://doi.org/10.1145/2207676. 2208649

9. Doris Adams Hill, Margaret M. Flores (2014) Comparing the Picture Exchange Communication System and the $\mathrm{Pad}^{\mathrm{TM}}$ for Communication of students with Autism Spectrum Disorder and Developmental Delay. URL: http://link.springer.com/article/10.1007/s11528014-0751-8

10. Maggie Ward, T. F. McLaughlin, Jennifer Neyman (2013) Use of an iPad application as functional communication for a five-year-old preschool student with autism spectrum disorder. URL: http://ijee.org/yahoo site admin/assets/docs/TIM 2.272133100.pdf https://doi.org/10.3109/07434618.2013.784930

11. David McNaughton, Janice Light (2013) The iPad and Mobile Technology Revolution: Benefits and Challenges for Individuals who require Augmentative and Alternative Communication. URL: http://www.tandfonline.com/doi/abs/10.3109/07434618.2013.784930

12. Amie M King, Melissa Thomeczek, Grayce Voreis, Victoria Scott (2013) iPad ${ }^{\circledR}$ use in children and young adults with Autism Spectrum Disorder: An observational study. URL: http://clt.sagepub.com/content/30/2/159.short

13. Sally Bereznak, Kevin M. Ayres, Linda C. Mechling, Jennifer L. Alexander (2012) Video Self-Prompting and Mobile Technology to Increase Daily Living and Vocational Independence for Students with Autism Spectrum Disorders. URL: http://link.springer.com/article/10.1007/s10882-012-9270-8

14. Debora M. Kagohara, Larah van der Meer, Donna Achmadi, Vanessa A. Green, Mark F. O’Reilly, Austin Mulloy, Giulio E. Lancioni, Russell Lang, Jeff Sigafoos (2010) Behavioral Intervention Promotes Successful Use of an iPod-Based Communication Device by an Adolescent With Autism. URL: http://ccs.sagepub.com/content/9/5/328.short

15. Larah van der Meer, Donna Achmadi, Manon Cooijmans, Robert Didden, Guilio E Lancioni, Mark F. O'Reilly, Laura Roche, Michelle Stevens, Amarie Carnett, Flaviu Hodis, Vanessa A. Green, Dean Sutherland, Russell Lang, Mandy Rispoli, Peter B. Marschik, Jeff Sigafoos (2015) An iPad-Based Intervention for Teaching Picture and Word Matching to a Student with ASD and Severe Communication Impairment. URL: http://link.springer.com/article/10.1007/s10882-014-9401-5 https://doi.org/10.1016/j.rasd. 2012.12.004

16. Leslie Neely, Mandy Rispoli, Siglia Camargo, Heather Davis, Margot Boles (2013) The effect of instructional use of an iPad on challenging behavior and academic engagement for two students with autism. URL: http://www.sciencedirect.com/science/ article/pii/S1750946712001626

17. Therese M. Cumming, Iva Strnadova, Sylvia Singh (2014) iPads as instructional tools to enhance learning opportunities for students with developmental disabilities: An action research project. URL: http://arj.sagepub.com/content/12/2/151.short 
18. Cathi Draper Rodríguez, PhD, Iva Strnadová, PhD, Therese Cumming, PhD (2013) Using iPads With Students With Disabilities: Lessons Learned from Students, Teachers, and Parents. URL: http://isc.sagepub.com/content/early/2013/11/01/1053451213509488.abstract

19. Cami E. Burton, MS, Darlene H. Anderson, PhD, Mary Anne Prater, PhD, Tina T. Dyches, PhD (2013) Video Self-Modeling on an iPad to Teach Functional Math Skills to Adolescents With Autism and Intellectual Disability. URL: http://foa.sagepub.com/content/early/2013/03/04/1088357613478829.abstract

20. Heather Duncan, Joo Tan (2012) A visual task manager application for individuals with autism. URL: http://dl.acm.org/citation.cfm?id=2184463

21. Iain Werry, Kerstin Dautenhahn (1999) Applying Mobile Robot Technology to the Rehabilitation of Autistic Children.URL: http://uhra.herts.ac.uk/handle/2299/1946

22. Juan Pablo Hourcade, Stacy R. Williams, Ellen A. Miller, Kelsey E. Huebner, Lucas J. Liang (2013) Evaluation of Tablet Apps to Encourage Social Interaction in Children with Autism Spectrum Disorders. URL: http://dl.acm.org/citation.cfm?id=2466438

23. Debora M. Kagohara (2011) Three Students with Developmental Disabilities Learn to Operate an iPod to Access Age-Appropriate Entertainment Videos. URL: http://link.springer.com/article/10.1007/s10864-010-9115-4 https://doi.org/10.1007/s10864 $\underline{-010-9115-4}$

\section{Authors}

Athanasios Drigas is a Research Director at IIT-N.C.S.R. Demokritos. He is the Coordinator of Telecoms Lab and founder of Net Media Lab since 1996. From 1990 to 1999 he was the Operational manager of the Greek Academic network. He has been the Coordinator of Several International Projects, in the fields of ICTs, and eservices (e-learning, e-psychology, e-government, e-inclusion, e-culture etc). He has published more than 270 articles, 7 books, 25 educational CD-ROMs and several patents. He has been a member of several International committees for the design and coordination of Network and ICT activities and of international conferences and journals. (e-mail: dr@iit.demokritos.gr).

Jenny Vlachou (MA in Teaching Methodology of Computer Science) is a Special Education ICT Teaching Professional, and scientific collaborator of Net Media Lab, NCSR Demokritos. (e-mail: jvlachou@gmail.com).

Submitted 08 June 2016. Published as resubmitted by the authors 23 September 2016. 